\section{A New Antifungal Sterol Sulfate, Sch 601324, from Chrysosporium sp.}

\author{
Shu-Wei Yang, * Alexei Buevich, Tze-Ming Chan, \\ Joseph Terracciano, Guodong Chen, David Loebenberg, \\ Mahesh Patel, Eric Boehm, Vincent Gullo, \\ Birendra Pramanik and Min Chu \\ Schering-Plough Research Institute, \\ 2015 Galloping Hill Road, Kenilworth, NJ 07033, USA
}

(Received for publication December 12, 2002)

Due to increasing of drug resistance from infectious fungal pathogens, searching for novel antifungal agents with different modes of action is continuously important in new drug development. An enzyme (1,3)- $\beta$-D-glucan synthase is one of the key enzymes in the synthesis of fungal cell wall. Three types of antifungal natural products with inhibition activity of cell wall $(1,3)-\beta$-D-glucan synthase have been discovered, including lipopeptides (pneumocandins and echinocandins), glycolipids (papulacandins) and terpenoids (enfumafungin, ascosteroside, ergokonin $\mathrm{A}$, and arundifungin). ${ }^{1)}$ Among these antifungal agents, caspofungin acetate (MK-0991), a semi-synthetic analogue of pneumocandins, has shown promising antifungal application in clinical trials, and has been launched as a parenteral antifungal agent. ${ }^{2)}$ In the course of our continuing search for novel antifungal agents, we have isolated a novel antifungal agent Sch 601324 (1), from a fungal culture Chrysosporium sp. (Family: Onygenaceae). Sch 601324 was identified as a sterol sulfate, structurally related to arundifungin (2). ${ }^{3,4)}$ In this paper, we describe the isolation and structure elucidation of 1 using high resolution ESMS and extensive NMR spectroscopic analysis.

Fermentation studies were carried out in shake flasks. Stock cultures were maintained as frozen whole broths at $-80^{\circ} \mathrm{C}$ in a final concentration of $10 \%$ glycerol. The inoculum medium contained: Proteus Peptone, $5 \mathrm{~g} ; \mathrm{NaCl}$, $5 \mathrm{~g}$; $\mathrm{KH}_{2} \mathrm{PO}_{4}, 5 \mathrm{~g}$; Yeast Extract, $3 \mathrm{~g}$; Cerelose, $20 \mathrm{~g}$; Soybean Grits, $5 \mathrm{~g}$; Antifoam, $1 \mathrm{ml}$; Tap $\mathrm{H}_{2} \mathrm{O}$ to 1 liter. The $\mathrm{pH}$ was adjusted to 7.2 prior to autoclaving. A $250 \mathrm{ml}$ Erlenmeyer flask containing $70 \mathrm{ml}$ of this medium was inoculated with $2.0 \mathrm{ml}$ of the stock culture. The flasks were incubated at $24^{\circ} \mathrm{C}$ on a rotary shaker at $250 \mathrm{rpm}$ for 96 hours. This seed culture $(2.5 \mathrm{ml})$ was used to inoculate another $250 \mathrm{ml}$ Erlenmeyer flask containing $70 \mathrm{ml}$ of the same seed medium and the flask was incubated, as above for 96 hours.

Five percent of the second germination was used to inoculate the fermentation medium containing: Oat Flour, $20 \mathrm{~g}$; Soy Flour, $20 \mathrm{~g}$; Yeast Extract, $2 \mathrm{~g}$, Corn Step Powder, $5 \mathrm{~g} ; \mathrm{K}_{2} \mathrm{HPO}_{4}, 11 \mathrm{~g} ; \mathrm{KH}_{2} \mathrm{PO}_{4} ; 4 \mathrm{~g}$; and $\mathrm{Tap} \mathrm{H}_{2} \mathrm{O}$ to 1 liter. The fermentation was carried out in a 2-liter Erlenmeyer flask containing $350 \mathrm{ml}$ of the fermentation medium. The flasks were incubated at $24^{\circ} \mathrm{C}$ on a rotary shaker at $250 \mathrm{rpm}$ for 120 hrous.

The fermentation culture broth ( $\sim 8$ liters) was stirred with $400 \mathrm{~g}$ of $\mathrm{NaCl}$ and 16 liters of acetonitrile. The organic layer was separated and dried in vacuum. The salt in the extract was further removed by a solid phase extraction (SPE) method. Extract was absorbed onto the polymeric resin, $\mathrm{CG161}(\sim 100 \mathrm{ml})$ and the $\mathrm{NaCl}$ salt was washed out with water $(200 \mathrm{ml})$. The absorbed organic material was removed from the resin with $150 \mathrm{ml}$ of $80 \%$ acetonitrile $(\mathrm{ACN})$. After drying in vacuum, $983 \mathrm{mg}$ of organic material was obtained. The organic material was fractionated on an

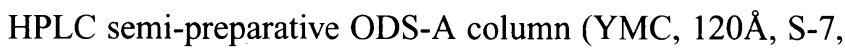
$2 \mathrm{~cm} \times 25 \mathrm{~cm}$ ). The column was eluted with a gradient of $\mathrm{ACN}-\mathrm{H}_{2} \mathrm{O}: 1 \sim 40 \%$ ACN in 50 minutes, then $40 \%$ isocratic for 20 minutes, and then $40 \sim 100 \% \mathrm{ACN}$ in another 50 minutes, with a flow rate of $15 \mathrm{ml} /$ minute. Fractions were collected $(13 \mathrm{ml} /$ fraction $)$ by a fraction

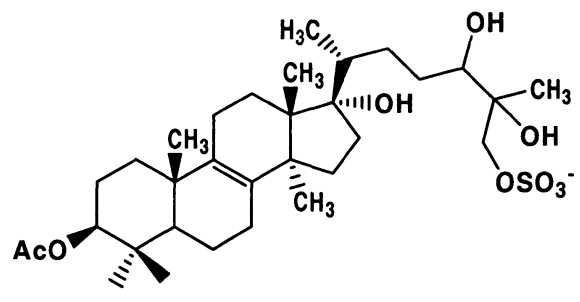

$\operatorname{Sch} 601324(1)$

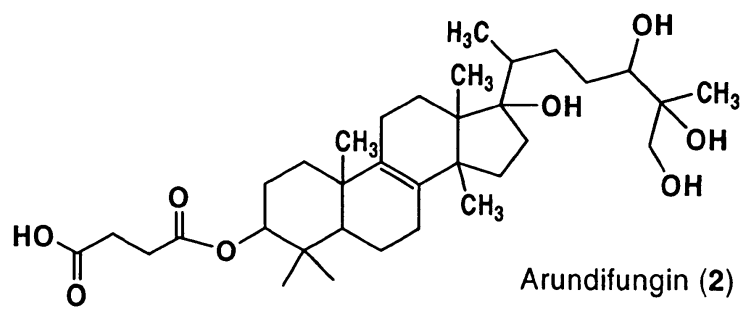

* Corresponding author: shu-wei.yang@spcorp.com 
collector. Pure 1 ( $\sim 1.0 \mathrm{mg})$ was obtained with each $150 \mathrm{mg}$ injection at retention time $\sim 63$ minutes as white amorphous powder. The procedure was repeated eight times, and all pure fractions containing 1 were combined to yield $7 \mathrm{mg}$ of material.

From high-resolution negative ESI-MS, the molecular formula of 1 was established as $\mathrm{C}_{32} \mathrm{H}_{53} \mathrm{O}_{9} \mathrm{~S}$ (Found 613.3409; calcd. 613.3415 for [M] ${ }^{-}$) suggesting one sulfate group in the molecule (performed on a PE Sciex QSTAR mass spectrometer; two internal standards, taurocholic acid and nitrazepan, were used in the negative ion ESI-HR-MS measurements). The structure of 1 was further elucidated by extensive NMR data analysis. Thirty two carbons were observed in the ${ }^{13} \mathrm{C}$ NMR spectrum (Table 1), suggesting a triterpene skeleton with two additional carbons. Highly overlapped proton signals in ${ }^{1} \mathrm{H}$ NMR (Table 1) can be interpreted and assigned to their adjacent carbons by HSQC analysis. The triterpene skeleton was mainly determined by interpretation of HMBC data. The significant 2- or 3-bond $\mathrm{H}-\mathrm{C}$ correlations were observed through the following seven methyl groups: $\mathrm{H}_{3}-19(\delta$ 0.95) to $\mathrm{C}-1$ ( $\delta 34.8), \mathrm{C}-5$ $(\delta$ 50.1), C-9 ( $\delta$ 135.4), and C-10 ( $\delta 36.4) ; \mathrm{H}_{3}-18(\delta$ 0.72) to $\mathrm{C}-12(\delta 25.0), \mathrm{C}-13, \mathrm{C}-14$ ( $\delta 49.2$ and 49.7$)$, and $\mathrm{C}-17$ $\left(\delta\right.$ 84.1); $\mathrm{H}_{3}-28$ ( $\delta$ 1.12) to C-8 $(\delta 133.2), \mathrm{C}-13, \mathrm{C}-14$, and C-15 $(\delta 31.1) ; \mathrm{H}_{3}-29(\delta 0.83)$ and $\mathrm{H}_{3}-30(\delta 0.82)$ to $\mathrm{C}-3(\delta$ 79.9), C-4 ( $\delta 37.4)$, and $\mathrm{C}-5 ; \mathrm{H}_{3}-21(\delta 0.85)$ to $\mathrm{C}-17, \mathrm{C}-20$ $\left(\delta\right.$ 42.6), and $\mathrm{C}-22\left(\delta\right.$ 29.9); $\mathrm{H}_{3}-27(\delta$ 0.97) to $\mathrm{C}-24(\delta$ $75.5), \mathrm{C}-25$ ( $\delta$ 73.1), and C-26 ( $\delta$ 70.7) (see Figure 1). These long range correlations combined with carbon and APT data allow us to determine the boldfaced fragments shown in Figure 1. The fragment pattern is a typical pattern of 3-hydroxyl-lanostanoid skeleton. This was confirmed by the following connectivity obtained from ${ }^{1} \mathrm{H}-{ }^{1} \mathrm{H}$ COSY and HSQC-TOCSY (Figure 1): $\mathrm{H}_{2}-2(\delta 1.59)$ to $\mathrm{H}-3(\delta 4.36)$; $\mathrm{H}-5(\delta 1.06)$ to $\mathrm{H}_{2}-6(\delta 1.47,1.64) ; \mathrm{H}_{2}-1(\delta 1.18,1.71)$ to $\mathrm{H}_{2}-2 ; \mathrm{H}_{2}-6$ to $\mathrm{H}_{2}-7(\delta 2.02) ; \mathrm{H}_{2}-11\left(\delta\right.$ 2.01) to $\mathrm{H}_{2}-12(\delta$ $1.35,2.19) ; \mathrm{H}_{2}-15(\delta 1.24,1.62)$ to $\mathrm{H}_{2}-16(\delta 1.87)$.

After the ring skeleton was determined, the structure of the side chain was established by the same strategy. From HMBC correlations mentioned previously, C-24 was adjacent to a quaternary oxygenated carbon (C-25), which was substituted with a terminal methyl group (C-27) and an oxygenated methylene carbon (C-26). The connectivity of $\mathrm{H}_{2}-22, \mathrm{H}_{2}-23$, and $\mathrm{H}-24$ was further resolved by HSQCTOCSY (see Figure 1). Thus the full skeleton was concluded.

An acetate and a sulfate groups remained to be assigned to two of the four oxygen positions. The acetate was assigned to $3-O$ position and the sulfate to $\mathrm{C}-26$ position based on the following evidence. Chemical shift of C-3 $(\delta$
Table 1. NMR spectral data for compound $\mathbf{1}$ in DMSO- $d_{6}{ }^{\mathrm{a}}$.

\begin{tabular}{|c|c|c|}
\hline $\mathrm{C} / \mathrm{H}$ no. & ${ }^{1} \mathrm{H}(\delta)$ & ${ }^{13} \mathrm{C}(\delta)$ \\
\hline $1 \alpha$ & $1.18, \mathrm{~m}$ & $34.8 \mathrm{t}$ \\
\hline $1 \beta$ & $1.71, \mathrm{~m}$ & \\
\hline 2 & $1.59, \mathrm{~m}$ & $23.8 \mathrm{t}$ \\
\hline 3 & 4.36, dd, J = 7.7, 8.6 & $79.9 \mathrm{~d}$ \\
\hline 4 & & $37.4 \mathrm{~s}$ \\
\hline 5 & $1.06, \mathrm{dd} J=12.7,1.8$ & $50.1 d$ \\
\hline \multirow[t]{2}{*}{6} & $1.47, \mathrm{~m}$ & $17.5 \mathrm{t}$ \\
\hline & $1.64, m$ & \\
\hline 7 & $2.02, m$ & $25.4 \mathrm{t}$ \\
\hline 8 & & $133.2 \mathrm{~s}$ \\
\hline 9 & & $135.4 \mathrm{~s}$ \\
\hline 10 & & $36.4 \mathrm{~s}$ \\
\hline 11 & $2.01, \mathrm{~m}$ & $20.4 \mathrm{t}$ \\
\hline \multirow[t]{2}{*}{12} & $2.19, \mathrm{~m}$ & $25.0 \mathrm{t}$ \\
\hline & $1.35, \mathrm{dd} J=12.9,8.7$ & \\
\hline 13 & & $49.7 \mathrm{~s}^{\star}$ \\
\hline 14 & & $49.2 \mathrm{~s}^{*}$ \\
\hline \multirow[t]{2}{*}{15} & $1.24, \mathrm{~m}$ & $31.1 \mathrm{t}$ \\
\hline & $1.62, \mathrm{~m}$ & \\
\hline 16 & $1.87, \mathrm{~m}$ & $39.5 \mathrm{t}$ \\
\hline 17 & & $84.1 \mathrm{~s}$ \\
\hline 18 & $0.72, \mathrm{~s}$ & $18.4 \mathrm{q}$ \\
\hline 19 & $0.95, \mathrm{~s}$ & $18.7 q$ \\
\hline 20 & $1.46, \mathrm{~m}$ & $42.6 \mathrm{~d}$ \\
\hline 21 & $0.85, \mathrm{~d}, J=6.6$ & $14.4 \mathrm{q}$ \\
\hline \multirow[t]{2}{*}{22} & $0.96, \mathrm{~m}$ & $29.9 \mathrm{t}$ \\
\hline & $1.74, \mathrm{~m}$ & \\
\hline \multirow[t]{2}{*}{23} & $0.94, \mathrm{~m}$ & $29.2 \mathrm{t}$ \\
\hline & $1.61, m$ & \\
\hline 24 & $3.32, \mathrm{~m}$ & $75.5 \mathrm{~d}$ \\
\hline 25 & & $73.1 \mathrm{~s}$ \\
\hline \multirow[t]{2}{*}{26} & $3.55, d, J=10.6$ & $70.7 t$ \\
\hline & $4.72, \mathrm{t}, J=10.6$ & \\
\hline 27 & $0.97, \mathrm{~s}$ & $21.4 \mathrm{q}$ \\
\hline 28 & $1.12, \mathrm{~s}$ & $26.6 \mathrm{q}$ \\
\hline 29 & $0.83, \mathrm{~s}$ & $27.7 q$ \\
\hline 30 & $0.82, \mathrm{~s}$ & $16.4 \mathrm{q}$ \\
\hline $\mathrm{CO}_{2} \mathrm{CH}_{3}$ & $2.00, \mathrm{~s}$ & $21.4 \mathrm{q}$ \\
\hline $\mathrm{CO}_{2} \mathrm{CH}_{3}$ & & $170.1 \mathrm{~s}$ \\
\hline $24-\mathrm{OH}$ & 4.12 bs & \\
\hline
\end{tabular}

${ }^{\mathrm{a}}$ Recorded on a Varian Unity 500 NMR instrument at $500 \mathrm{MHz}$ for ${ }^{1} \mathrm{H}$ and $125 \mathrm{MHz}$ for ${ }^{13} \mathrm{C}$, using standard Varian pulse sequence programs (VNMR Version 6.1 Software). $\delta$ in ppm; $J$ in $\mathrm{Hz}$. 
Fig. 1. 2D NMR correlations of $\mathbf{1}$.

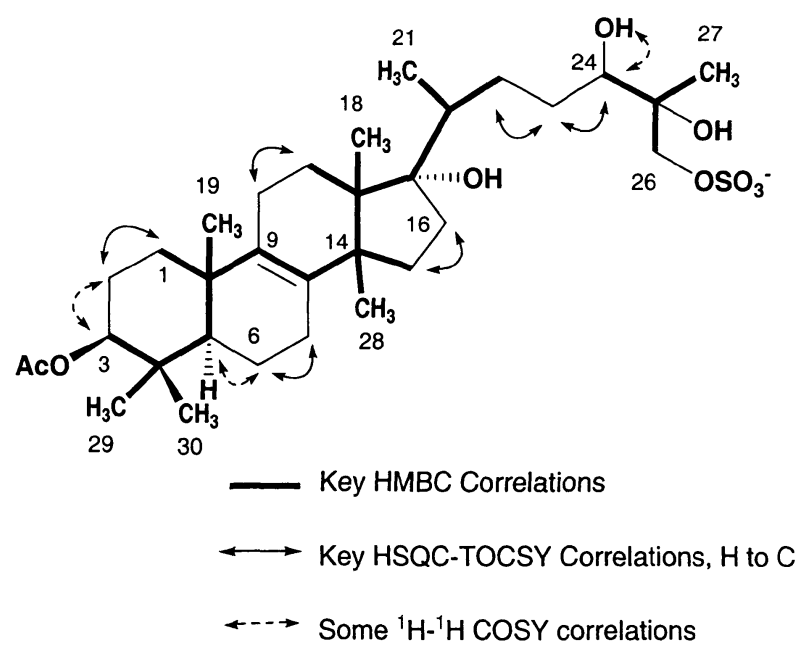

Fig. 2. Key NOE correlations of $\mathbf{1}$.

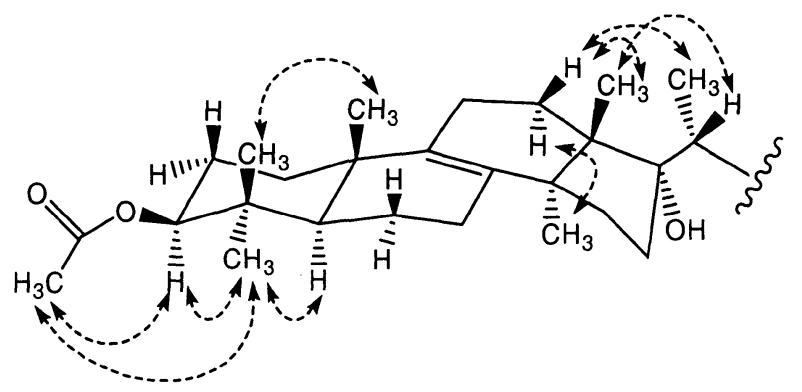

79.9) and H-3 ( $\delta 4.36)$ are typical for those of $3-\beta-O-A c$ lanostanoid comparing to those of the known analogues. ${ }^{5)}$ In addition, NOE correlations of the acetyl methyl to H-3 and $\mathrm{H}_{3}-30$ were observed in a ROESY spectrum. Thus, the acetate was assigned to 3- $O$ position. Compared to the known analogues, significant downfield shift of chemical shifts of $\mathrm{H}_{2}-26(\delta 3.55,4.72)$ and $\mathrm{C}-26(\delta 70.7)$ have confirmed that the sulfate group is on 26 position. ${ }^{6,7)}$

The relative stereochemistry of $\mathbf{1}$ was determined by the analyses of the ${ }^{1} \mathrm{H}-{ }^{1} \mathrm{H}$ coupling patterns (Table 1) and NOE data. Key NOE correlations are shown in Figure 2. Hydroxyl substitution on $\mathrm{C}-17$ was determined as $\alpha$ position as a result of the observation of $\gamma$ gauge effect on C-12 $(\delta 25.0, \Delta-6 \mathrm{ppm})$ and NOE correlations of $\mathrm{H}_{3}-18$ to $\mathrm{H}-20$ and $\mathrm{H}_{3}-21$. Thus, the structure elucidation of 1 was
Table 2. Antifungal activity of Sch 601324 , MIC-48h $(\mu \mathrm{g} / \mathrm{ml})$.

\begin{tabular}{lcc}
\hline \multicolumn{1}{c}{ Strain $^{\mathrm{c}}$} & SCH601324 & $\begin{array}{c}\text { Caspofungin } \\
\text { (control) }\end{array}$ \\
\hline Candida albicans (FLZ-S) & 1 & $<0.06$ \\
C.albicans (FLZ-R) & $0.5(1)^{\mathrm{a}}$ & $<0.06$ \\
C.dubliniensis (FLZ-R) & 8 & $<0.06$ \\
C.glabrata (FLZ-S) & $0.1(0.5)^{\mathrm{a}}$ & $<0.06$ \\
C.glabrata (FLZ-R) & $0.5(1)^{\mathrm{a}}$ & $<0.06$ \\
C.krusei & $2(16)^{\mathrm{a}}$ & 0.125 \\
Crypto.neoformans & 16 & 16 \\
S.cereviseae (S.S.) & $<0.06(4)^{\mathrm{a}}$ & $\mathrm{NT}^{\mathrm{b}}$ \\
\hline
\end{tabular}

${ }^{\mathrm{a}}$ MFC-24h in parentheses

${ }^{\mathrm{b}}$ NT-Not Tested

${ }^{c}$ FLZ-S: fluconazole sensitive; FLZ-R: fluconazole resistant; S.S.: super sensitive strain

completed. Sulfated and 17-hydroxyl substituted triterpenes are relatively unusual in microbial kingdom. The skeleton of Sch 601324 is closely related to arundifungin, whose stereochemistry was not addressed. ${ }^{3,4)}$

Compound 1 exhibited antifungal activity against various Candida strains. The MIC values were shown in Table 2. Standard compound, caspofungin, showed lower MIC values when tested under the same conditions. Sch 601324 did not show any inhibitory effect against tested Aspergillus strains and bacterial strains such as Staphylococcus aureus, Streptococcus pneumoniae, Escherichia faecalis, and Escherichia coli.

\section{Acknowledgement}

The authors are grateful to Ms. ReEna Patel for MIC data, Mr. ERIK LANGSDORF for culture fermentation, Mr. LEWIS B. FAN for culture extraction, and Ms. ElEANOR SHARGORODSKAYA for database search.

\section{References and Notes}

1) Onishi, J.; M. Meinz, J. Thompson, J. Curotto, S. Dreikorn, M. Rosenbach, C. Douglas, G. Abruzzo, A. Flattery, L. Kong, A. Cabello, F. Vicente, F. Pelaez, M. T. Diez, I. Martin, G. Bills, R. Giacobbe, A. Dombrowski, R. Schwartz, S. Morris, G. Harris, A. TSIPOURAS, K. WILSON \& M. B. KuRTZ: Discovery of novel antifungal $(1,3)-\beta$-D-glucan synthase inhibitors. Antimicrob. Agents Chemother. 44: 368 377, 2000

2) Keating, G. M. \& B. JaRvis: Caspofungin. Drugs 61: $1121 \sim 1129,2001$

3) Schwartz, R. E.; G. F. Bills, R. A. Giacobbe, J. M. Liesch, M. S. MeinZ, J. C. Onishi, D. L. Zink, A. 
Cabello, T. Diez, I. Martin, F. Vicente \& F. Pelaez: (Merck \& Co., Inc.) Antifungal agent. WO 9728180 A1, August 7, 1997

4) Liesch, J. M.; M. S. Meinz, J. C. Onishi, R. E. Schwartz, G. F. Bills, R. A. Giacobbe, D. L. Zink, A. Cabello, M. T. Diez, I. Martin, F. Pelaez \& F. VICENTE: (Merck \& Co., Inc.) Antifungal agent produced by Arthrinium arundinis ATCC 74359. U.S. 5,712,109, January 27, 1998

5) Martynow, J. \& Z. ParyzeK: Epoxidation-induced shifts in the carbon-13 NMR spectra of steroids: lanostane derivatives. Mag. Res. Chem. 27: 258 262, 1989

6) Fujita, A.; M. Arisawa, M. Saga, T. Hayashi \& N. MoritA: Two new lanostanoids from Ganoderma lucidum J. Nat. Prod. 49: 1122 1125, 1986

7) Min, B.-S.; N. Nakamura, H. Miyashiro, K.-W. Bae \& M. HATTORI: Triterpenes from the spores of Ganoderma lucidum and their inhibitory activity against HIV-1 protease. Chem. Pharm. Bull. 46: 1607 1612, 1998 